\title{
Experimental Determination of Three Hourly Refractivity of IDAH, Kogi State, Nigeria
}

\author{
Abdullahi, S. Ayegba \\ Engineering and space systems Department, National Space Research and Development Agency (NASRDA) and Eco Educational Consult, \\ Abuja, Nigeria
}

\begin{abstract}
The change in radio refractivity of an area affects the strength of radio frequency communication signals transmitted and/or received in the area, as refractivity is related to signal strength. The aim of this work is to determine how radio refractivity changes after a given time interval in a day. The data of temperature, pressure, and relative humidity recorded by a digital thermo-hygrometer mounted on a pole close to the ground level in Aija-Idah $\left(7.1114^{\circ} \mathrm{N}, 6.7356^{\circ}\right)$ of Kogi state was used to calculate the three hourly refractivity for two days (December 17 and 24, 2016) with one week interval. It was observed that the radio refractivity varied after each three hours interval, and the change is mostly a function of relative humidity. It was also observed that the refractivity in week 2 (harmattan day) was less than that of week 1 (day with no harmattam), hence allowing communication signal strength to travel farther than any other days without harmattan.
\end{abstract}

Keywords: Refraactivity, Harmattan, Relative humidity, Signal strengths

\section{Introduction}

Refraction is defined as the change in direction or bending of signal as it passes from one medium to another. It causes degradation in communication signal strength as well as communication loss in point to point communication links because change in atmospheric refractive index will cause the transmitted signal to divert from its original path, and hence will not reach the desired destination.

Radio refractivity is defined as the product of the refractive index less than one unit and one million. The ratio of the velocity of the radio propagation in free space to that in medium is called refractive index.

A radio waves propagating through the earth atmosphere will experience path bending due to inhomogeneous spatial distribution of the refractive index of air which causes adverse effects such as multipath fading and interference. These effect significantly impair radio communication, aerospace, environmental monitoring, disaster forecasting e.t.c. [Bawa Musa et al, 2015]

The effect of meteorological variable of pressure, temperature, and relative humidity on radio wave propagation at UHF and microwaves frequencies are analyzed from the study radio refractive index derived from these three parameters [Bean and Dutton, 1966]. Since these variables vary considerably daily and seasonally especially in the tropics, quantitative knowledge of refractivity variations is required in order to be able to design reliable and efficient radio communication (terrestrial and satellite) system [Bawa Musa et al, 2015].

Surface radio refractivity Ns is known to have high correlation with radio field strength values (Bean, B. R. and B. A. Cahoon, 1961], thus knowing the radio refractivity of a place especially how it varies with some meteorological parameters will help in planning of communication systems. This is because changes in the value of the radio refractive index in the troposphere can curve the path of the propagating radio wave. The atmosphere radio refractive index depends on air temperature, humidity, atmospheric pressure and water vapour pressure. Even small changes in any of these variables can make a significant influence on radio-wave propagation, because radio signals can be refracted over the whole signal path [Priestley and Hill, 1985].

Research works relating to this have been carried out by many scientists and researchers in some parts of Nigeria such as; "Study of Average Hourly Variations of Radio Refractivity Variations across Some Selected Cities in Nigeria" by Bawa Musa, Dr. Ayantunji B.G, Dr. MaiUnguwa H., Dr. Galadanchi G.S.M., and Shamsuddeen Idris Mu'azu in, 2015. Their works made use of three years of meteorological data measured from January 2010 to December 2013 using Vantage Pro 2 automatic weather station which was installed at each location. It was observed according to them that average hourly variations of refractivity in the dry season was due to the variations of the wet component (humidity). Also, in the work "Diurnal And Seasonal Variation Of Surface Refractivity Over Nigeria" by B. G. Ayantunji, P. N. Okeke and J. O. Urama, in 2011 which made use of four years in-situ meteorological data from eight location over Nigeria- Nsukka, Sokoto, Minna, Akure, Jos, Lagos, PortHarcourt and Makurdi, it was observed that "The diurnal variation seems to be mainly driven by the dry component in the rainy season and the wet component in the dry season".

This research work was carried out in Idah local government area of Kogi state, North central Nigeria. The data used was measured by a digital thermo-hygrometer with a data logger which was positioned close to ground level to measure temperature, pressure and relative humidity. The study area has a coordinate point of latitude $7.1114^{\circ} \mathrm{N}$ and longitude $6.7356^{\circ} \mathrm{E}$. 


\section{International Journal of Science and Research (IJSR) \\ ISSN (Online): 2319-7064}

Index Copernicus Value (2015): 78.96 | Impact Factor (2015): 6.391

\section{Study Area}

Idah is a town in kogi state, Nigeria on the eastern bank of River Niger in the middle belt of Nigeria. Idah which shares boundaries with Igalamela/Odolu, Ibaji, Ofu local governments and River Niger by its west separating it from Agenebode, Edo state has the population of 79,815 according to 2006 census. Idah, an old river port hosts the Federal Polytechnic Idah, College of Health Science and Technology, National Open University, National Television Authority (NTA), many primary and secondary schools, and is the headquarters of Igala kingdom, where the traditional ruler; the Attah Igala, currently Dr Idakwo Ameh Oboni II resides.

\section{Materials and Method}

\subsection{Materials}

This research work made use of primary data- temperature, pressure and relative humidity measured by a digital thermohygrometer mounted in the study area on the 17th and 24th December 2016. Although, general data which covers this location can be obtained from the Nigeria Meteorological Agency (NIMET) office, it may not specifically take care of Idah, since the data will be mainly for Kogi state in general or Lokoja. For this reason, and having the interest of Idah local government for the research, especially as it is hosts the NTA Idah, and many telecommunication (GSM) devices in addition to its busy nature and fast expansion, there was need for an experimental setting up of equipment for the measurement of such atmospheric data in the area, which was the basic ideas behind this approach.

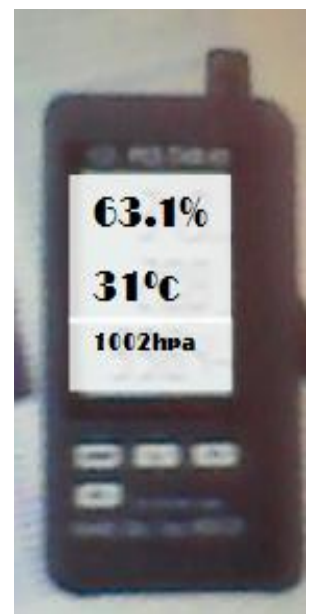

Figure 1: Digital thermo-hygrometer

The parameters were measured at the interval of three hours beginning from $3.00 \mathrm{am}$ to $12.00 \mathrm{am}$ on each of the two days, once in a week and at interval of seven days (one week). The instrument (digital thermo-hygrometer) was located close to ground level at a location- Aija $\left(7.1114^{\circ} \mathrm{N}, 6.7356^{\circ} \mathrm{E}\right)$, Attah Igala's palace close, to measure the atmospheric parameters, which was stored by a memory card of the device. The instrument which makes use of long lasting rechargeable battery has the capacity to record hourly atmospheric parameters but three hourly parameters were selected as it was the focus of this work. Recorded data were transferred into a computer where it was converted to a tabula form.

\subsection{Methods}

The calculations of various parameters were done in Microsoft excel workbook using their various formulas. Graphs and tables were also prepared using the excel package.

\section{Analysis of the refractivity calculations:}

a. Determination of saturated vapour pressure $\left(\mathbf{e}_{\mathbf{s}}\right)$ : The saturated vapour pressure is the pressure of a liquid when it is in equilibrium with the liquid phase. It is expressed mathematically as;

$$
e_{s}=6.11 \exp \left[\frac{17.26(T-273.16)}{T-35.87}\right]
$$

Where $T$ is the air temperature in Kelvin $(\mathrm{K}), e_{s}$ is the saturated vapour pressure in hectopascal (hpa) and exp is exponential $(\exp =2.718)$.

b. Determination of vapour pressure (e): Vapour pressure is defined as the measurement of the amount of moisture in the air. Vapour pressure is expressed mathematically as;

$$
e=e_{s} \times \frac{H}{100}
$$

Where $H$ is the relative humidity in percent, $e$ is the vapour pressure in hectopascal $(h p a)$ and $e_{s}$ is the saturated vapour pressure.

c. Determination of Radio Refractivity (N): Radio refractivity is the physical property of the medium as determined by its index of refraction. It is the product of the refractive index less than one unit and one million. Radio refractivity is expressed mathematically as;

$$
N=77.7 \frac{P}{T}+3.73 \times 10^{5} \frac{e}{T^{2}} \quad \text {---- } 4
$$

Where $P$ is the air pressure in (hpa), $e$ is the vapour pressure in hectopascal $(h p a)$ and $T$ is the air temperature in Kelvin $(K)$.

Table 1: Temperature, pressure and humidity data for December 17, 2016

\begin{tabular}{|c|c|c|c|c|c|}
\hline S.No & Time & $\begin{array}{c}\text { Time } \\
(24 \mathrm{hr})\end{array}$ & $\begin{array}{c}\text { Temp } \\
\left({ }^{0} \mathrm{c}\right)\end{array}$ & $\begin{array}{c}\text { Press } \\
(\mathrm{hpa})\end{array}$ & $\begin{array}{c}\text { RH } \\
(\%)\end{array}$ \\
\hline 1 & $3.00 \mathrm{am}$ & 3 & 21.9 & 1003.3 & 87 \\
\hline 2 & $6.00 \mathrm{am}$ & 6 & 21.3 & 1004.8 & 96 \\
\hline 3 & $9.00 \mathrm{am}$ & 9 & 30.7 & 1005.8 & 60 \\
\hline 4 & $12.00 \mathrm{pm}$ & 12 & 35.4 & 1003.5 & 42 \\
\hline 5 & $3.00 \mathrm{pm}$ & 15 & 36.3 & 1000.9 & 32 \\
\hline 6 & $6.00 \mathrm{pm}$ & 18 & 31.1 & 1002.3 & 35 \\
\hline 7 & $9.00 \mathrm{pm}$ & 21 & 25.5 & 1003.7 & 68 \\
\hline 8 & $12.00 \mathrm{am}$ & 24 & 23.9 & 1003.1 & 70 \\
\hline
\end{tabular}




\section{International Journal of Science and Research (IJSR) \\ ISSN (Online): 2319-7064 \\ Index Copernicus Value (2015): 78.96 | Impact Factor (2015): 6.391}

Table 2: Temperature, pressure and humidity data for December 24, 2016

\begin{tabular}{|c|c|c|c|c|c|}
\hline S.No & Time & $\begin{array}{c}\text { Time } \\
(24 \mathrm{hr})\end{array}$ & $\begin{array}{c}\text { Temp } \\
\left({ }^{0} \mathrm{c}\right)\end{array}$ & $\begin{array}{c}\text { Press } \\
(\mathrm{hpa})\end{array}$ & $\begin{array}{c}\text { RH } \\
(\%)\end{array}$ \\
\hline 1 & $3.00 \mathrm{am}$ & 3 & 22.3 & 1003.3 & 87 \\
\hline 2 & $6.00 \mathrm{am}$ & 6 & 22.0 & 1003.6 & 76 \\
\hline 3 & $9.00 \mathrm{am}$ & 9 & 32.9 & 1004.9 & 37 \\
\hline 4 & $12.00 \mathrm{pm}$ & 12 & 36.1 & 1002.8 & 31 \\
\hline 5 & $3.00 \mathrm{pm}$ & 15 & 36.0 & 1000.5 & 31 \\
\hline 6 & $6.00 \mathrm{pm}$ & 18 & 30.4 & 1001.5 & 44 \\
\hline 7 & $9.00 \mathrm{pm}$ & 21 & 25.5 & 1003.3 & 54 \\
\hline 8 & $12.00 \mathrm{am}$ & 24 & 23.2 & 1003.2 & 65 \\
\hline
\end{tabular}

\section{Results and Discussions}

Table 3: Refractivity (N) for December 17, 2016

\begin{tabular}{|c|c|c|c|c|c|c|}
\hline S.No & Time & $\begin{array}{c}\text { Time } \\
(24 \mathrm{hr})\end{array}$ & $\begin{array}{c}\text { Temp } \\
(\mathrm{c} \text { c) }\end{array}$ & $\begin{array}{c}\text { Pressure } \\
(\mathrm{hpa})\end{array}$ & $\begin{array}{c}\text { RH } \\
(\%)\end{array}$ & $N$ \\
\hline 1 & $3.00 \mathrm{am}$ & 3 & 21.9 & 1003.3 & 87 & 361.5744 \\
\hline 2 & $6.00 \mathrm{am}$ & 6 & 21.3 & 1004.8 & 96 & 369.1447 \\
\hline 3 & $9.00 \mathrm{am}$ & 9 & 30.7 & 1005.8 & 60 & 363.6538 \\
\hline 4 & $12.00 \mathrm{pm}$ & 12 & 35.4 & 1003.5 & 42 & 346.7488 \\
\hline 5 & $3.00 \mathrm{pm}$ & 15 & 36.3 & 1000.9 & 32 & 326.1245 \\
\hline 6 & $6.00 \mathrm{pm}$ & 18 & 31.1 & 1002.3 & 35 & 319.2500 \\
\hline 7 & $9.00 \mathrm{pm}$ & 21 & 25.5 & 1003.7 & 68 & 353.3697 \\
\hline 8 & $12.00 \mathrm{am}$ & 24 & 23.9 & 1003.1 & 70 & 349.5984 \\
\hline
\end{tabular}

Refractivity (N) for December 24, 2016

\begin{tabular}{|c|c|c|c|c|c|c|}
\hline S.No & Time & $\begin{array}{c}\text { Time } \\
(24 \mathrm{hr})\end{array}$ & $\begin{array}{c}\text { Temp } \\
(\mathrm{Oc})\end{array}$ & $\begin{array}{c}\text { Pressure } \\
(\mathrm{hpa})\end{array}$ & $\begin{array}{c}\text { RH } \\
(\%)\end{array}$ & $N$ \\
\hline 1 & $3.00 \mathrm{am}$ & 3 & 22.3 & 1003.3 & 87 & 363.3537 \\
\hline 2 & $6.00 \mathrm{am}$ & 6 & 22.0 & 1003.6 & 76 & 349.6914 \\
\hline 3 & $9.00 \mathrm{am}$ & 9 & 32.9 & 1004.9 & 37 & 328.3501 \\
\hline 4 & $12.00 \mathrm{pm}$ & 12 & 36.1 & 1002.8 & 31 & 323.7207 \\
\hline 5 & $3.00 \mathrm{pm}$ & 15 & 36.0 & 1000.5 & 31 & 322.8770 \\
\hline 6 & $6.00 \mathrm{pm}$ & 18 & 30.4 & 1001.5 & 44 & 333.1888 \\
\hline 7 & $9.00 \mathrm{pm}$ & 21 & 25.5 & 1003.3 & 54 & 334.2336 \\
\hline 8 & $12.00 \mathrm{am}$ & 24 & 23.2 & 1003.2 & 65 & 341.0149 \\
\hline
\end{tabular}

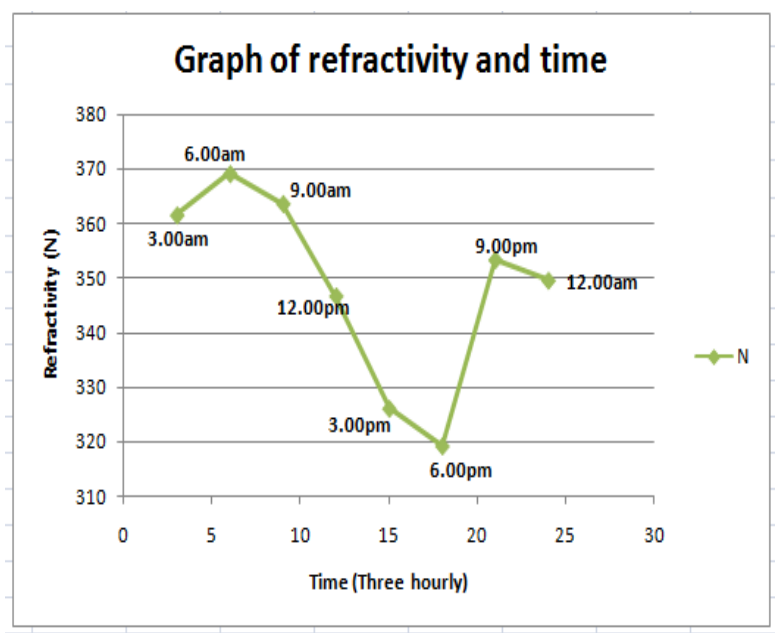

( $\mathrm{N}=$ Refractivity)

Figure 2: Graph of refractivity and time for December 17

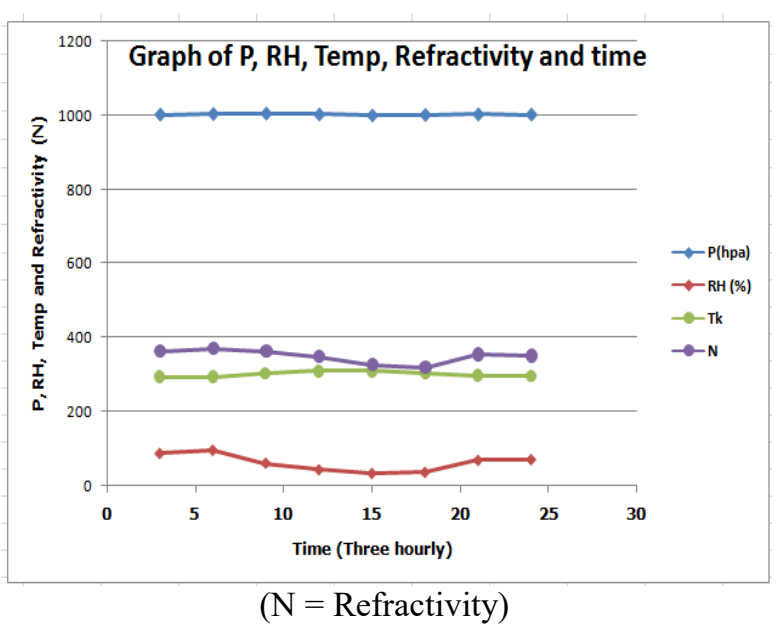

Figure 3: Graph of refractivity and meteorological data for December 17

Table 3 shows the three hourly refractivity for December 17 , 2016. This was supposed to be the period of hamattarn in the study period (Idah area of Kogi state) but there was no hamattarn on this day when the experiment was carried out. The data of temperature, pressure and relative humidity by collected data-logger thermo-hygrometer on the above date were used to calculate the vapour pressure, saturated vapour pressure and radio refractivity of the study area. The refractivity increases between 3.0am and 6am, and then decreases slowly until 9am when the decrement becomes faster. This continues until it reaches the minimum value at $6 \mathrm{pm}$, which is $319.25 \mathrm{~N}$-units. This occurred when the relative humidity is very low, though not the lowest as other factors also contribute to change in refractivity other than relative humidity. It then rises sharply to $9.0 \mathrm{pm}$ and decreases throughout the next three hours. The radio refractivity as observed from this analysis is seen to vary within the time interval as the relative humidity. The relative humidity continues to decrease from $3 \mathrm{am}$ to $3 \mathrm{pm}$ when it assumes its minimum value of $32 \%$, and then starts increasing till $12 \mathrm{am}$. In the same way, the refractivity decreases from $3 \mathrm{am}$ but beyond $3 \mathrm{pm}$ as its minimum value occurs at $6 \mathrm{pm}(319.25 \mathrm{~N}$-units) and then increases till $12 \mathrm{am}$ This is shown in figure 2 . The three hourly variation of the radio refractivity for this period was caused mostly by relative humidity as can be noticed in figure 3 .

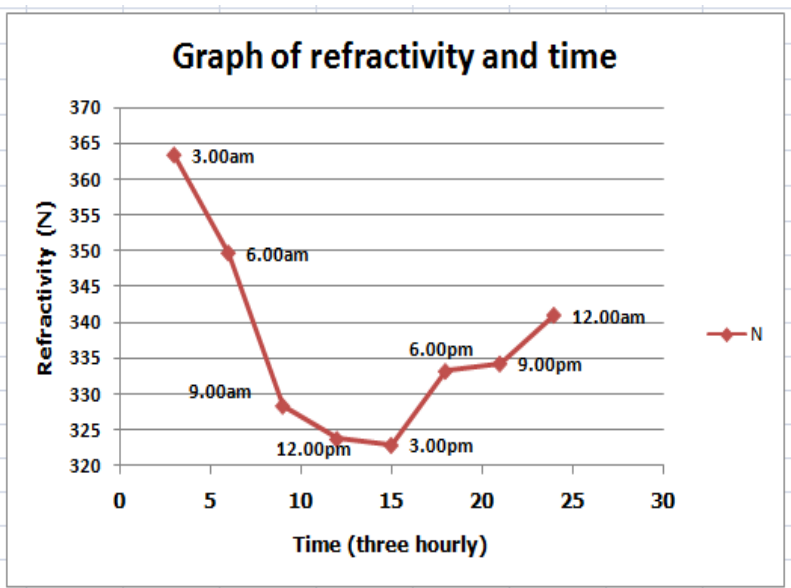

Figure 4: Graph of refractivity and time for December 24 $(\mathrm{N}=$ refractivity) 


\section{International Journal of Science and Research (IJSR) \\ ISSN (Online): 2319-7064}

Index Copernicus Value (2015): 78.96 | Impact Factor (2015): 6.391

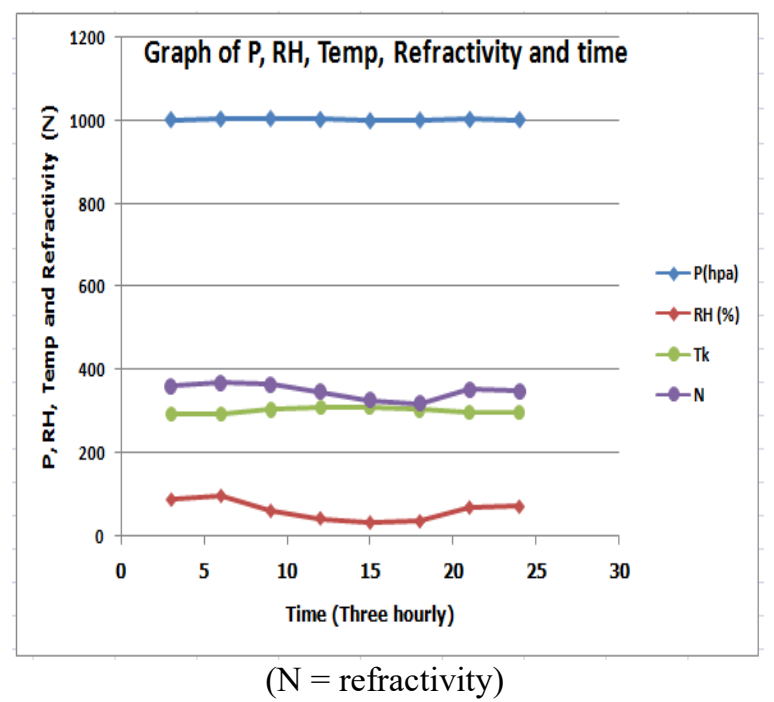

Figure 5: Graph of refractivity and meteorological data for December 17

Table 4 shows the radio refractivity calculated from the data of temperature, pressure and relative humidity obtained from the thermo-hygrometer data-logger of December 24, 2016. This data was taken during hamattarn period. The result of the calculations shows a continuous decrease in radio refractivity from $3.00 \mathrm{am}$ till $3.00 \mathrm{pm}$ and then starts rising till $12.00 \mathrm{am}$. The refractivity decreases sharply from $3.0 \mathrm{am}$ to 9.00am when it starts to decrease slowly until it reaches its minimum value of $322.877 \mathrm{~N}$-units at $3.00 \mathrm{pm}$. It then increases sharply from $3.00 \mathrm{pm}$ till $6.00 \mathrm{pm}$ when it starts to increase slowly until $9.00 \mathrm{pm}$ after which it again increases sharply until $12.00 \mathrm{am}$. This is shown in figure 4 .

From table 4, it can be observed that the variation of the three hourly refractivity is mainly a function of the relative humidity as refractivity is seen to decrease (and increase) with decrease (and increase) in relative humidity. Although, other parameters can also influence the radio refractivity of an area, the effect of relative humidity is more pronounced as seen in figure 5. Figure 5 shows the relationship between the temperature, pressure, relative humidity and radio refractivity. The figure shows that the radio refractivity is mostly related to relative humidity than the other parameters such as temperature and pressure.

By relating figure 3 and figure 5, similar trend can be observed. There are variations in refractivity at each interval such that the refractivity on each of the two days changes with the change in relative humidity. This is in accordance with the work of Bawa Musa et al in which they observed that "The average hourly variations of refractivity in the dry season is largely as a result of the variations of the wet component (humidity)". The little differences noticed especially between 3.00am and 6.00am was due to the difference in the pattern of change in relative humidity. In the week without hamattarn, the relative humidity increases from $3.00 \mathrm{am}$ to $6.00 \mathrm{am}(87 \%$ to $96 \%)$, while in the week when there was hamattarn, the relative humidity decreases from $3.00 \mathrm{am}$ to $6.00 \mathrm{am}(87 \%$ to $76 \%)$. The hamattarn haze caused the change in the pattern of relative humidity between $3.00 \mathrm{am}$ to $6.00 \mathrm{am}$ in particular, and the general relative humidity values on that day as the relative humidity values in week 2 were less than those in week 1 . The difference in the two days between $9.00 \mathrm{pm}$ to $12.00 \mathrm{am}$ was due to other factors resulting in change in radio refractivity other than relative humidity.

\section{Conclusion}

The data of temperature, pressure and relative humidity recorded from the thermo-hygrometer for two weeks, one day in each week were used to calculate the three hourly refractivity of the study area. The results for the two days show the change in radio refractivity at each of the three hour interval in almost the same trend. In other word, the radio refractivity of the area was changing at every time interval (three hourly) on both days. These changes were observed to be caused mainly by relative humidity, though other factor(s) contributed to its change as seen between $9.00 \mathrm{pm}$ to $12.00 \mathrm{am}$ in week two.

Conclusively, it can be stated that daily radio refractivity changes with time and its change is mostly a function of the relative humidity. Furthermore, the less refractivity observed during harmattan periods allows signal to travel longer and stronger without series of bending or refractions, thus allowing many radio stations to be received by radio set during harmattan than any other periods. The result of this work will help network planners and radio engineers to predict the extent a communication signal can cover because of very high correlation between signal strength and radio refractivity according to many research works.

\section{Recommendations}

This research work was carried out in dry season, and most specifically, a harmattan period even though there was no noticeable hamattarn during the first week. Also, the data (temperature, pressure and relative humidity) used for the work was for two weeks and taken once in each of the weeks. It is recommended that the work be carried out during rainy season, and also should involve the study period of at least two successive months.

\section{Acknowledgement}

My sincere appreciation to Attah Igala; Dr Idakwo Ameh Oboni II for his contribution towards the publication of this work, and thanks also to all science staff of Mathson Comprehensive High school, Idah Kogi state for their assistance in the setting up of the equipment.

\section{References}

[1] Bawa Musa, Dr. Ayantunji B.G, Dr. Mai-Unguwa H., Dr. Galadanchi G.S.M., and Shamsuddeen Idris Mu'azu (2015). "Study of Average Hourly Variations of Radio Refractivity Variations across Some Selected Cities in Nigeria", IOSR Journal of Applied Physics.

[2] Bean, B. R., Dutton, E. J., (1966). Radio Meteorology, Dover Edition, New York, USA.

[3] Bean, B. R. and B. A. Cahoon (1961). "Correlation of monthly median transmission loss and refractive index profile characteristics,"

\section{Volume 6 Issue 1, January 2017




\section{International Journal of Science and Research (IJSR) \\ ISSN (Online): 2319-7064}

Index Copernicus Value (2015): 78.96 | Impact Factor (2015): 6.391

[4] B. G. Ayantunji and P. N. Okeke, J. O. Urama (2011). "Diurnal And Seasonal Variation Of Surface Refractivity Over Nigeria". Progress In Electromagnetics Research B.

[5] Falodun, S. E. and M. O. Ajewole, (2006) "Radio refractive index in the lowest $100 \mathrm{~m}$ layer of the troposphere in Akure," South-western Journal of Atmospheric and Solar-terrestrial Physics.

[6] Ikeh U. Chinelo and Okeke C. Chukwunike, (2016). "The Study of Surface Radio Refractivity in Awka, South Eastern Nigeria”. Journal of Geography, Environment and Earth Science International

[7] Priestley JT, Hill RJ (1985). Measuring high-frequency refractive index in the surface layer. J. Atmos. Oceanic Technol.

[8] Serdege D, Ivanovs G. (2007). Refraction seasonal variation and that influence onto $\mathrm{GHz}$ range microwaves availability. Electronics and Electrical Engineering.

[9] Titus, A. A. and M. O. Ajewole, (2008) "Vertical profile of radio refractivity gradient in Akure, south-west Nigeria," Progress In Electromagnetics Research C.

[10] Trewartha GT (1970). The Earth's Problem Climates. The University of Wisconsin Press. 